\title{
Assessment of sleep disorders and proposed percentiles for adolescents
}

\author{
Rossana Gómez Campos, M.D. ${ }^{a}$, Evandro Lazari, M.D. ${ }^{b}$, Miguel de Arruda, M.D. ${ }^{b}$, \\ Jaime Pacheco Carrillo, M.D. ', Camilo Urra-Albornoz, Magisterd and \\ Marco Cossio-Bolaños, M.D. ${ }^{e f f}$
}

\begin{abstract}
Objectives. The objectives of this study included: a) to develop a valid and reliable self-reporting instrument to assess sleep disorders among Chilean adolescent students and b) to develop percentiles for age and sex.

Methodology. This was a descriptive, crosssectional study in 2310 adolescent students conducted in the Maule Region, Chile. The sleep disorder self-report was developed considering five categories: duration, alterations, breathing problems, fatigue, and stimulant use. The instrument was validated using a confirmatory factor analysis. Reliability was assessed based on internal consistency. Percentiles were developed using the LMS method (L: lambda, asymmetry; $\mathrm{M}$ : mu, median; S: sigma, coefficient of variation). Results. Questions 3, 9, and 12 showed saturation values below 0.40 , while the rest had saturation values above 0.41 . The Kaiser-Meyer-Olkin measure of adequacy was 0.749 and the test of sphericity $\mathrm{X}_{2}$ was 4790.09 ; the percentage of variance accounted for $62.1 \%$. Cronbach's alpha ranged between 0.71 and 0.76 .

Conclusion. The self-report developed to measure sleep disorders in adolescents is valid and reliable for its use in health, education, and sports science programs. Percentiles should be used to identify normal patterns and/or sleep disorders by sex and age.

Key words: sleep, self-report, validation studies,
\end{abstract} surveys and questionnaires, adolescent.

http:/ / dx.doi.org/10.5546/aap.2019.eng.73 Católica del Maule, Talca, Chile.

f. Centro de Investigación Especializada MAROSCINEMAROS, SAC, Arequipa, Perú.

E-mail address:

Rossana Gómez

Campos, M.D.:

rossaunicamp@gmail.

com

Funding:

None.

Conflict of interest:

None.

Received: 3-10-2018

Accepted: 8-15-2018

\section{INTRODUCTION}

Sleep is a vital physiological process for the comprehensive health of human beings. ${ }^{1}$ It is affected by biological and environmental factors, ${ }^{2}$ which generally translates into somnolence and fatigue, a worsening of academic performance, a higher risk for anxiety, depression, and substance abuse, as well as obesity, diabetes, and cardiovascular disease. ${ }^{2-3}$

In recent years, sleep disorders in adolescents have gained attention among researchers from different regions worldwide. ${ }^{2-4}$ This is because the lack of sleep is a public health problem not only present in adults, but also in children and adolescents.

Essentially, the bibliography has described that approximately $25-40 \%$ of adolescents had sleep disorders at some point during their growth and development. ${ }^{5}$ Actually, the onset of puberty leads to hormonal changes that delay circadian rhythms, causing a physiological impulse towards late sleep and waking hours. ${ }^{6}$

As a consequence, sleep patterns in adolescents deserve to be studied because the identification and treatment of sleep disorders may help to improve poor sleep habits before adult age. ${ }^{78}$ However, to this end, it is necessary to have specific instruments targeted at the student population with valid and reliable psychometric properties.

At present, many questionnaires are being developed, adapted and/ or translated but their psychometric qualities, structure, validity, and reliability are superficial; ${ }^{4}$ therefore, it is necessary to conduct an adequate outcome measure operationalization, whose theoretical information 
may help to understand sleep disorders during adolescence given that the structure of questionnairesfor school-age participants is usually widely variable in terms of content and categories. ${ }^{9}$ In this regard, it is necessary to develop local questionnaires adapted to different realities, which would prevent fundamental concerns and doubts, especially in the case of instruments adapted or translated from and/or used in other settings.

As a consequence, the assessment of sleep disorders is not only relevant for the identification and diagnosis of prevalence values, but also for the definition of normal values in adolescents and the classification of severity to a greater or lesser extent. Therefore, the study had the following objectives: a) to develop a valid and reliable selfreporting instrument to assess sleep disorders among Chilean adolescent students and b) to develop percentiles for age and sex.

\section{METHODOLOGY Participants}

This was a descriptive, cross-sectional study in 2310 adolescent students (1224 boys and 1086 girls) conducted in the Maule Region, Chile. Four municipalities were considered for the study: Cauquenes, Curicó, Linares, and Talca. Eight municipal schools were analyzed.

This region is considered predominantly agricultural. The capital city is Talca and it is located $243 \mathrm{~km}$ south of Santiago, the capital city of Chile.

The student population was made up of 19250 adolescents aged 11.0-18.9 years (10 203 boys and 9047 girls). The sample size was estimated in a probabilistic fashion (stratified by age and sex) (95\% confidence interval). A representative sample of 2310 students $(12.0 \%)$ was obtained: 1224 boys $(6.4 \%)$ and 1086 girls $(5.6 \%)$. The number of subjects in the sample was directly proportional to the overall population. The average age was $14.41 \pm 1.87$ years in boys and $14.20 \pm 1.91$ years in girls.

The study included students aged 11.0 to 18.9 years whose families did not smoke. Subjects who had cough, fever, and stomach problems in the previous month and those who did not give their approval for study participation were excluded.

Before instrument administration, investigators organized a talk for parents and/ or legal guardians to explain the study objectives and assessment methods. All parents signed an informed consent to authorize the administration of questionnaires. The possibility of obtaining adolescents' assent was also considered. Then, authorizations were obtained from the Municipal Administration of Education (Dirección de Administración de Educación Municipal, DAEM) of Talca and from the principals of the eight schools included in the study. The study was also approved by the Ethics Committee of Universidad Autónoma de Chile and was conducted in accordance with the Declaration of Helsinki.

\section{Procedures}

The survey technique was used to measure the studied outcome measure. The designed instrument was made up of two parts: a) demographic data (date of birth, sex, house location, physical activity, and attendance to a regular checkup) and b) self-report on sleep disorder content. Instrument content was based on the theoretical foundations found in the bibliography, ${ }^{10,11}$ which helped to develop the scale's conceptual framework. Table 1 shows the instrument's operationalization and organization into categories and subcategories. This instrument was designed based on five categories: sleep duration (SD), sleep alterations (SA), breathing problems (BP), feeling of fatigue (FF), and stimulant use (SU).

Each category included a set of questions about what had occurred in the past month. All questions were organized using a Likert-like scale and had up to three possible answers. Only one option could be chosen.

The self-report was completed with pen and paper in class at the corresponding school, during morning school hours (8:00 AM-12:30 PM, Mondays through Fridays). Four highlyexperienced survey-takers were in charge of the measurement process. They guided adolescents on how to complete the questionnaire and cleared their doubts or helped to solve any common problem. The process lasted 10 to 15 minutes.

The self-report was construct-validated (confirmatory factor analysis [CFA]). Reliability was assessed based on internal consistency. The scale's cut-off points were determined based on age and sex percentiles: < p15, no disorder; $\geq$ p15-p85, moderate disorder; and $>$ p85, severe disorder (Table 1).

\section{Data analysis}

Data normalization was verified using 
the Kolmogorov-Smirnov test. A descriptive statistical analysis was performed to establish frequencies, percentages, range, arithmetic mean, and standard deviation. Frequency differences were determined using the $X_{2}(p<0.05)$. The construct was validated using the multivariate CFA method (extraction of principal components technique), followed by the Varimax rotation and the Kaiser-Meyer-Olkin (KMO) measure. Factor loadings (eigenvalues) and the percentage of variance were also determined. Reliability was established using Cronbach's alpha coefficient. The smoothed percentile distribution was developed using the least-mean-square algorithm (LMS). ${ }^{12}$ The $\mathrm{p} 15, \mathrm{p} 50$, and $\mathrm{p} 85$ percentiles for age and sex were estimated. Data were normalized for sex and each age group. A Box-Cox power transformation was performed in advance. To this end, the maximum penalized likelihood estimation was implemented to develop three smoothed curves: $\mathrm{L}(\mathrm{t})$ asymmetry, $\mathrm{M}(\mathrm{t})$ median, and $S(t)$ coefficient of variation. Estimations were done using Excel spreadsheets and the SPSS 18.0 software.

\section{RESULTS}

Figure 1 describes the characteristics of the studied sample. Most students, both girls and boys, lived in urban areas. In addition, boys $(23.4 \%)$ were more inclined to doing physical activity than girls $(17.7 \%)$, but attended a regular checkup less frequently than girls $(10.9 \%$ versus $15.4 \%)$.

In relation to construct validity, CFA values were described as factor loadings (saturations) and reliability values were expressed with Cronbach's alpha. After the Varimax rotation with Kaiser normalization, it was possible to identify that questions 3, 9, and 12 showed saturation values below 0.40 , so they were eliminated from the questionnaire. The percentage of variance, at this time, was $58.1 \%$; after leaving only 21 questions in the instrument, whose factor loadings ranged between 0.41 and 0.74 $(p<0.001)$, the percentage of variance reached $62.1 \%$. The KMO measure of adequacy was 0.749 , the test of sphericity $X_{2}$ was 4790.09 $(p=0.000)$, and the eigenvalues ranged between 1.3 and 1.8. In relation to the reliability of the self-

TABLE 1. Operationalization of the studied outcome measure

\begin{tabular}{|c|c|c|}
\hline Indicators & No. & Questions \\
\hline \multirow[t]{5}{*}{ Sleep duration } & 1 & How many hours, approximately, do you sleep overnight? \\
\hline & 2 & How long does it take you to fall asleep after going to bed? \\
\hline & 3 & $\begin{array}{l}\text { If you happen to wake up in the middle of the night, how long does it take you to fall } \\
\text { back to sleep? }\end{array}$ \\
\hline & 4 & When you wake up the next day, how long does it take you to get out of bed? \\
\hline & 5 & Do you nap during the day? \\
\hline \multirow[t]{5}{*}{ Sleep alterations } & 6 & How often do you wake up in the middle of the night while you sleep? \\
\hline & 7 & Do you often wake up to use the bathroom during the night? \\
\hline & 8 & In general, do you have nightmares? \\
\hline & 9 & Do you usually sleep alone? \\
\hline & 10 & Do you feel like you move while you sleep? \\
\hline \multirow[t]{5}{*}{ Breathing problems } & 11 & Do you feel that you breathe normally while you sleep? \\
\hline & 12 & Do you usually cough while you sleep? \\
\hline & 13 & Do you feel that you snore while you sleep? \\
\hline & 14 & How often do you snore? \\
\hline & 15 & In general, do others wake you up because you are snoring? \\
\hline \multirow[t]{4}{*}{ Feeling of fatigue } & 16 & When you wake up in the morning, do you feel rested? \\
\hline & 17 & Do you feel tired during the day? \\
\hline & 18 & Have you felt down lately? \\
\hline & 19 & In general, do you feel that you want to rest (take a nap) while doing your everyday activities? \\
\hline \multirow[t]{5}{*}{ Stimulant use } & 20 & Do you usually take any type of sleep medicine? \\
\hline & 21 & Do you often have energy drinks during the day? \\
\hline & 22 & Do you use any food supplement? \\
\hline & 23 & In the past 30 days, how often did you drink alcoholic beverages? \\
\hline & 24 & Do you smoke? \\
\hline
\end{tabular}


perception scale, the Cronbach's alpha values were acceptable. Values ranged between $r=0.71$ and 0.76 (Figure 2).

The graphics for the five categories and the total scale are shown in Figures 3 and 4. Percentiles smoothed with the LMS method (p15, p50, and p85) are shown in Table 2. In relation to SD and $\mathrm{FF}$, the percentiles showed that values increased with age in both boys and girls; however, the SU category showed increasing but less marked values. In relation to SA, the values for boys remained relatively stable up to 14 years old, then fell slightly at 15 years old and stabilized around 18 years old. However, the values observed for girls increased up to 13 years old and then stabilized as of 14 years up to 18 years. In relation to $\mathrm{BP}$, boys showed decreasing values between 11 and 12 years old, which then stabilized up to 16 years and then increased slightly up to 18 years. In girls, these values remained stable as of 11 years up to 17 years. At 18 years old, values reduced slightly. In general, the sleep disorder self-perception scale showed that values increased with chronological age.

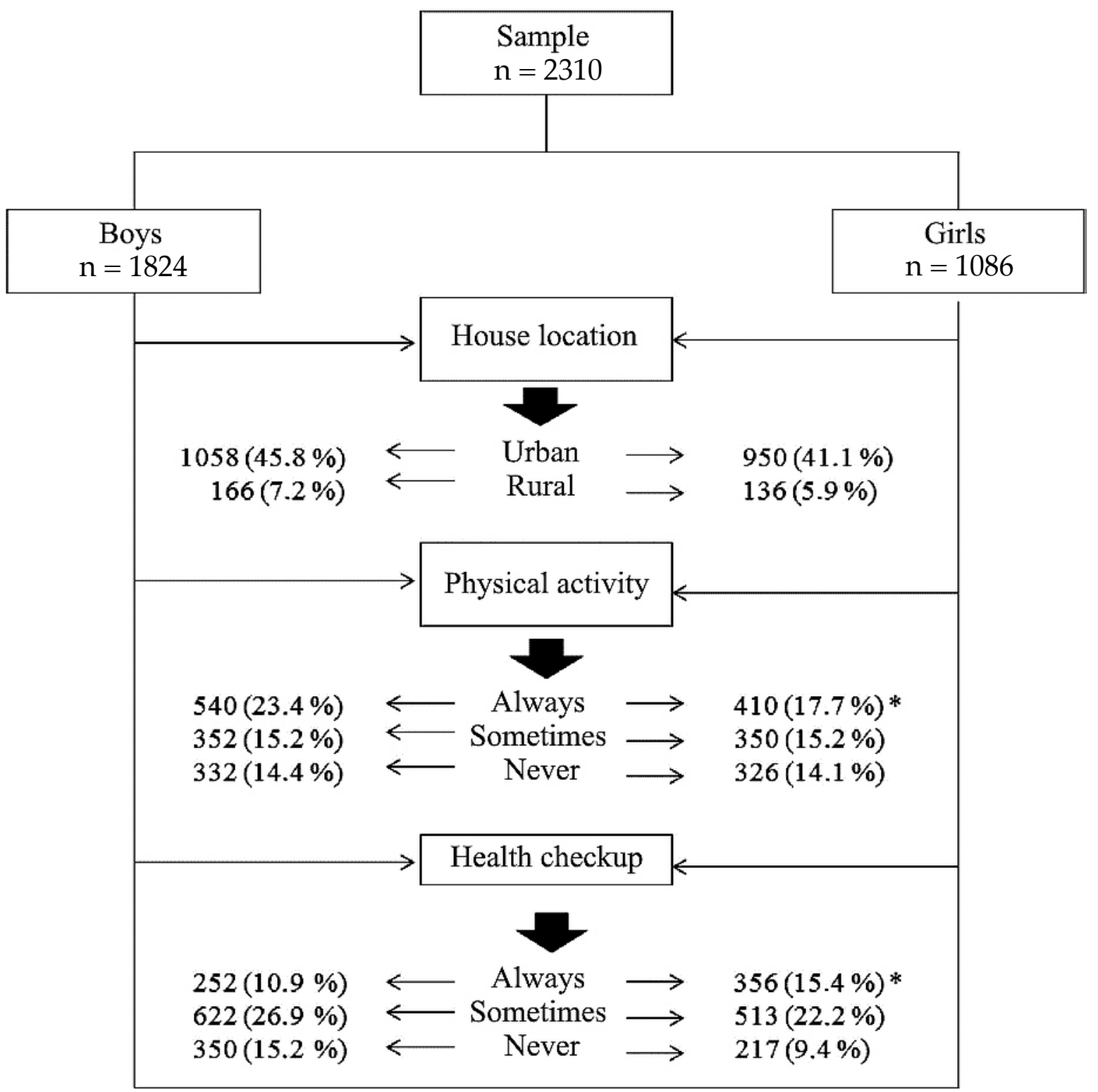




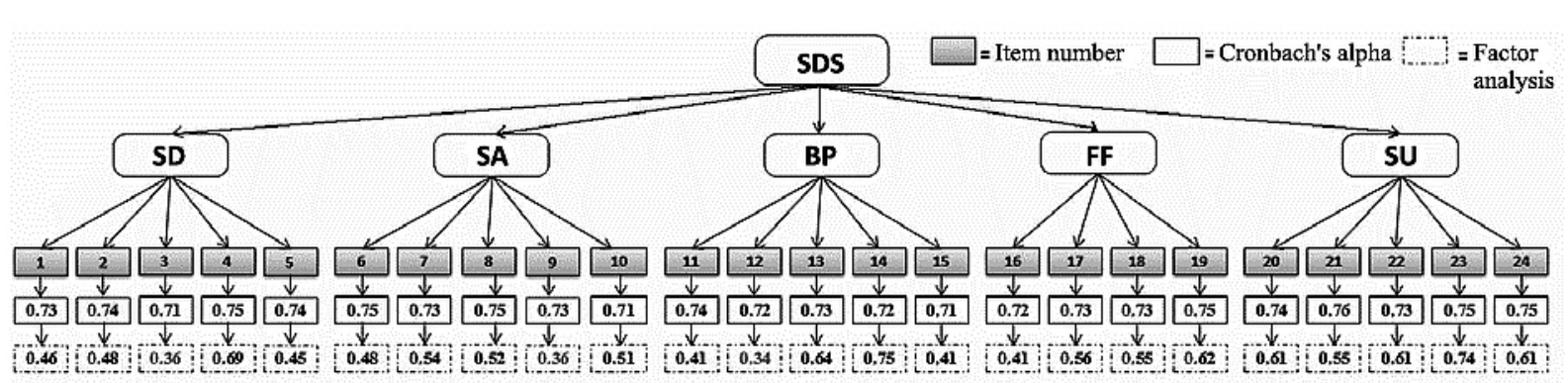

SDS: sleep disorder scale; SD: sleep duration (18.2\%); SA: sleep alterations (15.0\%); BP: breathing problems (12.1\%); FF: feeling of fatigue $(9.0 \%)$; SU: stimulant use $(7.8 \%)$.

FIGURE 3. Percentile curves ( 15 , p50, and p85) for boys, using the LMS method for category, age, and sex
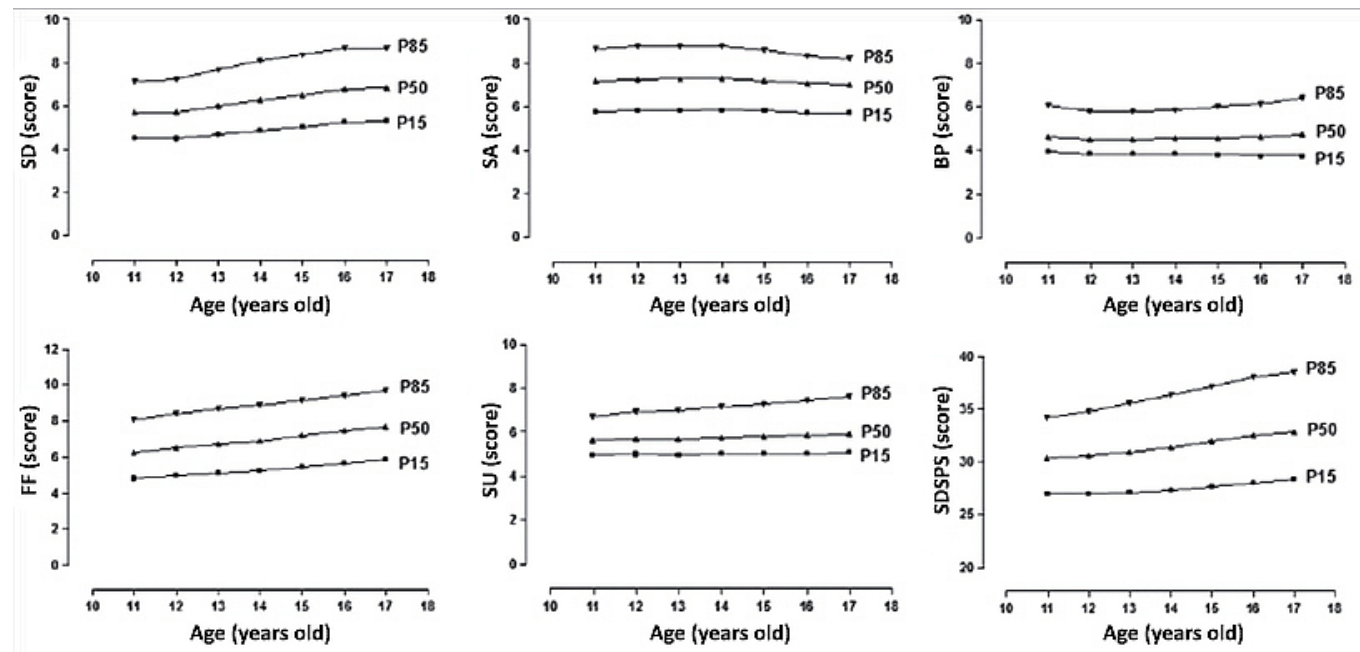

SD: sleep duration; SA: sleep alterations; BP: breathing problems; FF: feeling of fatigue; SU: stimulant use; SDSPS: Sleep Disorder Self-Perception Scale.

FIGURE 4. Percentile curves ( $p 15, p 50$, and p85) for girls, using the LMS method for category, age, and sex
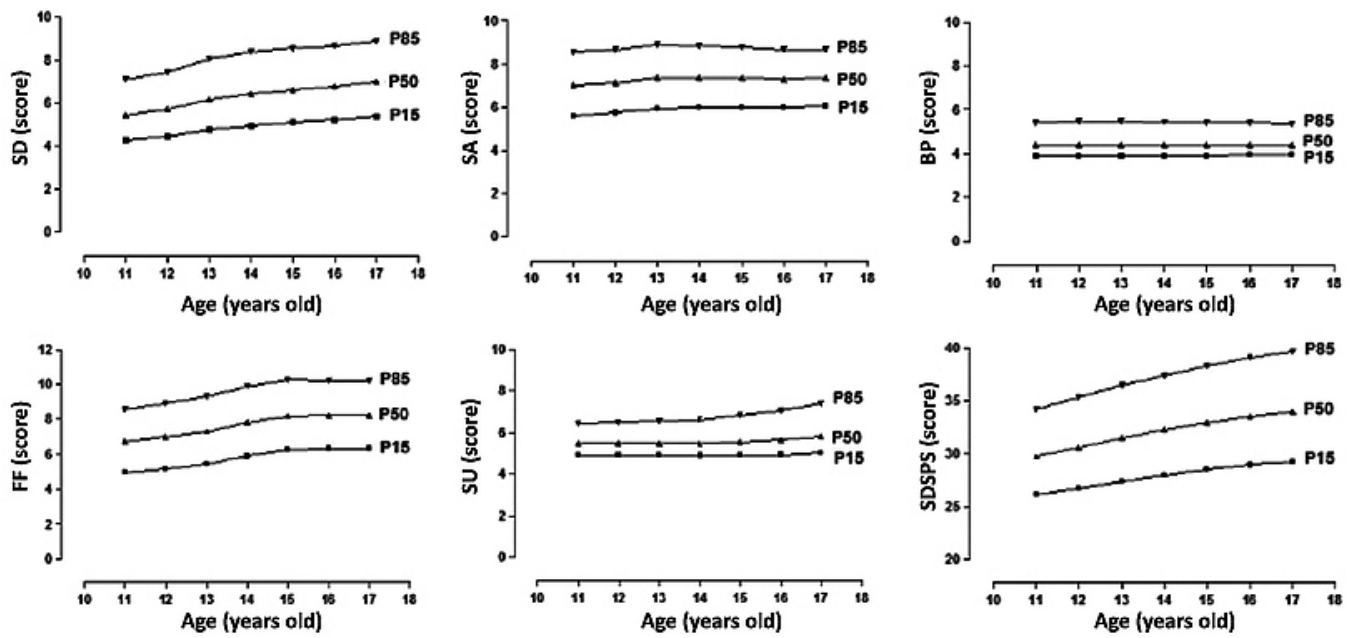

SD: sleep duration; SA: sleep alterations; BP: breathing problems; FF: feeling of fatigue; SU: stimulant use; SDSPS: Sleep Disorder Self-Perception Scale. 
TABLE 2. Smoothed percentile distribution for the sleep disorder self-perception scale by category, age and sex

\begin{tabular}{|c|c|c|c|c|c|c|c|c|c|c|c|c|c|c|}
\hline $\begin{array}{l}\text { Age } \\
\text { (years) }\end{array}$ & $\mathbf{n}$ & $\mathbf{L}$ & $\mathbf{M}$ & $S$ & P15 & P50 & P85 & $\mathbf{n}$ & $\mathbf{L}$ & $\mathbf{M}$ & $S$ & P15 & P50 & P 85 \\
\hline & & & & Boys & & & & & & & Girls & & & \\
\hline \multicolumn{15}{|c|}{ Sleep duration } \\
\hline $11.0-11.9$ & 150 & 0.15 & 5.69 & 0.22 & 5 & 6 & 7 & 133 & -0.39 & 5.45 & 0.24 & 4 & 5 & 7 \\
\hline $12.0-12.9$ & 165 & 0.05 & 5.71 & 0.23 & 4 & 6 & 7 & 187 & -0.26 & 5.74 & 0.25 & 4 & 6 & 7 \\
\hline $13.0-13.9$ & 165 & 0.00 & 5.99 & 0.24 & 5 & 6 & 8 & 186 & -0.14 & 6.17 & 0.25 & 5 & 6 & 8 \\
\hline $14.0-14.9$ & 188 & 0.03 & 6.27 & 0.25 & 5 & 6 & 8 & 156 & -0.03 & 6.46 & 0.25 & 5 & 6 & 8 \\
\hline $15.0-15.9$ & 209 & 0.12 & 6.51 & 0.25 & 5 & 7 & 8 & 133 & 0.08 & 6.63 & 0.25 & 5 & 7 & 9 \\
\hline $16.0-16.9$ & 168 & 0.24 & 6.79 & 0.24 & 5 & 7 & 9 & 117 & 0.17 & 6.79 & 0.25 & 5 & 7 & 9 \\
\hline $17.0-17.9$ & 99 & 0.36 & 6.84 & 0.24 & 5 & 7 & 9 & 105 & 0.23 & 6.99 & 0.24 & 5 & 7 & 9 \\
\hline 18.0-18.9 & 80 & 0.47 & 6.88 & 0.23 & 5 & 7 & 9 & 69 & 0.26 & 7.28 & 0.24 & 6 & 7 & 9 \\
\hline \multicolumn{15}{|c|}{ Sleep alterations } \\
\hline $11.0-11.9$ & 150 & 0.63 & 7.17 & 0.20 & 6 & 7 & 9 & 133 & 0.51 & 7.00 & 0.20 & 6 & 7 & 9 \\
\hline $12.0-12.9$ & 165 & 0.63 & 7.25 & 0.20 & 6 & 7 & 9 & 187 & 0.48 & 7.13 & 0.20 & 6 & 7 & 9 \\
\hline $13.0-13.9$ & 165 & 0.70 & 7.27 & 0.20 & 6 & 7 & 9 & 186 & 0.51 & 7.34 & 0.19 & 6 & 7 & 9 \\
\hline $14.0-14.9$ & 188 & 0.84 & 7.28 & 0.19 & 6 & 7 & 9 & 156 & 0.58 & 7.34 & 0.19 & 6 & 7 & 9 \\
\hline $15.0-15.9$ & 209 & 1.04 & 7.20 & 0.19 & 6 & 7 & 9 & 133 & 0.69 & 7.35 & 0.18 & 6 & 7 & 9 \\
\hline $16.0-16.9$ & 168 & 1.28 & 7.05 & 0.18 & 6 & 7 & 8 & 117 & 0.82 & 7.30 & 0.18 & 6 & 7 & 9 \\
\hline $17.0-17.9$ & 99 & 1.58 & 7.02 & 0.17 & 6 & 7 & 8 & 105 & 0.97 & 7.37 & 0.17 & 6 & 7 & 9 \\
\hline $18.0-18.9$ & 80 & 1.89 & 7.14 & 0.16 & 6 & 7 & 8 & 69 & 1.13 & 7.67 & 0.16 & 6 & 8 & 9 \\
\hline \multicolumn{15}{|c|}{ Breathing problems } \\
\hline $11.0-11.9$ & 150 & -2.55 & 4.63 & 0.19 & 4 & 5 & 6 & 133 & -3.78 & 4.37 & 0.14 & 4 & 4 & 5 \\
\hline $12.0-12.9$ & 165 & -2.45 & 4.50 & 0.19 & 4 & 5 & 6 & 187 & -3.54 & 4.40 & 0.14 & 4 & 4 & 5 \\
\hline $13.0-13.9$ & 165 & -2.31 & 4.50 & 0.19 & 4 & 5 & 6 & 186 & -3.40 & 4.39 & 0.15 & 4 & 4 & 5 \\
\hline $14.0-14.9$ & 188 & -2.05 & 4.55 & 0.19 & 4 & 5 & 6 & 156 & -3.47 & 4.38 & 0.15 & 4 & 4 & 5 \\
\hline $15.0-15.9$ & 209 & -1.67 & 4.60 & 0.21 & 4 & 5 & 6 & 133 & -3.63 & 4.39 & 0.14 & 4 & 4 & 5 \\
\hline $16.0-16.9$ & 168 & -1.24 & 4.63 & 0.23 & 4 & 5 & 6 & 117 & -3.81 & 4.39 & 0.14 & 4 & 4 & 5 \\
\hline $17.0-17.9$ & 99 & -0.92 & 4.75 & 0.25 & 4 & 5 & 6 & 105 & -4.01 & 4.38 & 0.13 & 4 & 4 & 5 \\
\hline $18.0-18.9$ & 80 & -0.65 & 4.84 & 0.27 & 4 & 5 & 7 & 69 & -4.23 & 4.33 & 0.13 & 4 & 4 & 5 \\
\hline \multicolumn{15}{|c|}{ Feeling of fatigue } \\
\hline $11.0-11.9$ & 150 & 0.09 & 6.26 & 0.25 & 5 & 6 & 8 & 133 & 0.77 & 6.71 & 0.26 & 5 & 7 & 9 \\
\hline $12.0-12.9$ & 165 & 0.19 & 6.54 & 0.25 & 5 & 7 & 8 & 187 & 0.69 & 6.97 & 0.26 & 5 & 7 & 9 \\
\hline $13.0-13.9$ & 165 & 0.28 & 6.73 & 0.25 & 5 & 7 & 9 & 186 & 0.67 & 7.31 & 0.26 & 5 & 7 & 9 \\
\hline $14.0-14.9$ & 188 & 0.39 & 6.91 & 0.25 & 5 & 7 & 9 & 156 & 0.70 & 7.81 & 0.25 & 6 & 8 & 10 \\
\hline $15.0-15.9$ & 209 & 0.54 & 7.18 & 0.25 & 5 & 7 & 9 & 133 & 0.77 & 8.20 & 0.24 & 6 & 8 & 10 \\
\hline $16.0-16.9$ & 168 & 0.66 & 7.47 & 0.25 & 6 & 7 & 9 & 117 & 0.83 & 8.22 & 0.23 & 6 & 8 & 10 \\
\hline $17.0-17.9$ & 99 & 0.72 & 7.71 & 0.24 & 6 & 8 & 10 & 105 & 0.88 & 8.23 & 0.23 & 6 & 8 & 10 \\
\hline $18.0-18.9$ & 80 & 0.76 & 8.02 & 0.24 & 6 & 8 & 10 & 69 & 0.92 & 8.55 & 0.22 & 7 & 9 & 11 \\
\hline \multicolumn{15}{|c|}{ Stimulant use } \\
\hline $11.0-11.9$ & 150 & -2.57 & 5.62 & 0.14 & 5 & 6 & 7 & 133 & -3.58 & 5.47 & 0.12 & 5 & 5 & 6 \\
\hline $12.0-12.9$ & 165 & -2.56 & 5.68 & 0.15 & 5 & 6 & 7 & 187 & -3.46 & 5.47 & 0.12 & 5 & 5 & 6 \\
\hline $13.0-13.9$ & 165 & -2.57 & 5.68 & 0.15 & 5 & 6 & 7 & 186 & -3.36 & 5.50 & 0.13 & 5 & 6 & 7 \\
\hline $14.0-14.9$ & 188 & -2.55 & 5.75 & 0.16 & 5 & 6 & 7 & 156 & -3.27 & 5.49 & 0.14 & 5 & 6 & 7 \\
\hline $15.0-15.9$ & 209 & -2.51 & 5.81 & 0.17 & 5 & 6 & 7 & 133 & -3.17 & 5.55 & 0.14 & 5 & 6 & 7 \\
\hline $16.0-16.9$ & 168 & -2.44 & 5.84 & 0.18 & 5 & 6 & 7 & 117 & -3.00 & 5.66 & 0.16 & 5 & 6 & 7 \\
\hline $17.0-17.9$ & 99 & -2.30 & 5.92 & 0.18 & 5 & 6 & 8 & 105 & -2.70 & 5.82 & 0.17 & 5 & 6 & 7 \\
\hline $18.0-18.9$ & 80 & -2.11 & 6.03 & 0.19 & 5 & 6 & 8 & 69 & -2.30 & 6.04 & 0.18 & 5 & 6 & 8 \\
\hline \multicolumn{15}{|c|}{ Total scale } \\
\hline $11.0-11.9$ & 150 & -0.17 & 30.34 & 0.12 & 27 & 30 & 34 & 133 & -0.58 & 29.69 & 0.13 & 26 & 30 & 34 \\
\hline $12.0-12.9$ & 165 & -0.20 & 30.56 & 0.12 & 27 & 31 & 35 & 187 & -0.53 & 30.52 & 0.14 & 27 & 31 & 35 \\
\hline $13.0-13.9$ & 165 & -0.27 & 30.97 & 0.13 & 27 & 31 & 36 & 186 & -0.43 & 31.47 & 0.14 & 27 & 31 & 36 \\
\hline $14.0-14.9$ & 188 & -0.32 & 31.41 & 0.14 & 27 & 31 & 36 & 156 & -0.35 & 32.22 & 0.14 & 28 & 32 & 37 \\
\hline $15.0-15.9$ & 209 & -0.32 & 31.94 & 0.14 & 28 & 32 & 37 & 133 & -0.30 & 32.94 & 0.14 & 29 & 33 & 38 \\
\hline $16.0-16.9$ & 168 & -0.32 & 32.50 & 0.15 & 28 & 33 & 38 & 117 & -0.28 & 33.46 & 0.14 & 29 & 33 & 39 \\
\hline $17.0-17.9$ & 99 & -0.33 & 32.87 & 0.15 & 28 & 33 & 39 & 105 & -0.29 & 33.91 & 0.15 & 29 & 34 & 40 \\
\hline $18.0-18.9$ & 80 & -0.33 & 33.30 & 0.15 & 29 & 33 & 39 & 69 & -0.29 & 34.66 & 0.15 & 30 & 35 & 41 \\
\hline
\end{tabular}

$\mathrm{L}=$ asymmetry; $\mathrm{M}=$ median; $\mathrm{S}=$ variation coefficient; $\mathrm{p}$ : percentile. 


\section{DISCUSSION}

This study demonstrated that the sleep disorder self-report scale was valid. The scale's factor structure confirmed the five operationalized categories (SD, SA, BP, FF, and $\mathrm{SU})$. For the 24 questions proposed initially, the percentage of variance was $58.1 \%$; however, once the three items with saturation values below 0.40 (questions 3, 6, and 9) were eliminated, the percentage of variance increased significantly to $62.2 \%$.

In fact, factor loadings observed in this study were similar to those seen in other studies with comparable objectives in relation to instrument development. ${ }^{13-15}$ These outcomes have evidently demonstrated an adequate theoretical agreement with the corresponding proposed categories. For this reason, saturation values above 0.41 clearly reflected homogeneity in each of the five operationalized categories with the corresponding items (questions).

Previous studies ${ }^{14,16}$ also evidenced a percentage of explained variance and eigenvalues that were similar to those of this study. This is a clear sign that the self-report scale displays construct validity, although further studies are required using other validation techniques, such as criterion validity with laboratory and/or field measurements.

In relation to reliability, in this study we used the Cronbach's alpha because of its close relation to the saturation values reported during the CFA process. ${ }^{17}$ In this regard, acceptable reliability values in general ranged between 0.70 and $0.90 .^{18}$ Actually, this study reported a reliability between 0.71 and 0.76 , which demonstrated the scale's moderate reproducibility.

Basically, several studies have used internal consistency as a criterion that is easily used and implemented to demonstrate instrument reliability; some studies have reported relatively similar values, ${ }^{19,20}$ while others showed higher values. ${ }^{13,14}$ In spite of this, the proposed instrument met the minimum requirements to reflect its reproducibility. Even at the time of developing the scale, simply written and easily understandable questions and the length of the questionnaire were taken into consideration because these factors helped to reduce bias, as described by Gregory. ${ }^{21}$ Therefore, the instrument we developed was reliable in terms of internal consistency, although future studies may consider other criteria, such as testing-retesting reliability, to verify outcome stability.
In brief, given the adequate psychometric properties in terms of validity and reliability of the proposed self-report, in this study we used the LMS method to develop percentiles for sex and age. Curves were smoothed with this method, and even the extremes of percentiles were estimated more effectively compared to other methods. ${ }^{22}$

This new percentile-based tool may help professionals in the education, health, and sports sciences to identify, classify, and monitor sleep disorders among adolescent students. In this regard, the proposed self-report scale may be interpreted based on individual scores, with the highest value pointing to a severe sleep disorder and the lowest value indicating that there is no disorder at all.

Actually, several international studies, regardless of the instrument used, have demonstrated that insufficient sleep is associated with obesity and cardiovascular diseases, ${ }^{23,24}$ as well as a poor academic performance, selective attention, ${ }^{25}$ symptoms of depression and anxiety. 26,27

Therefore, it has been suggested that sleep disorders may be more frequent among adolescents than adults. ${ }^{28}$ So they should be diagnosed and monitored frequently for an early detection, especially within epidemiological contexts where the lack of time and sophisticated equipment and the restricted availability of qualified personnel hinder the possibility of assessing sleep disorders in an objective manner.

In fact, the proposed instrument and its respective percentiles may help to establish the clinical suspicion of sleep disorders in general, and it may even help to analyze how sleep progresses by category (SD, SA, BP, FF, and SU). It also provides valuable information on the development and specific variability of sleep.

In general, sleep-related percentiles are useful for health science professionals, especially those who study sleep problems in pediatric practice. ${ }^{29}$ In addition, considering the five operationalized categories plotted using percentiles, they could be used in adolescents from other regions whose characteristics are similar to those included in this project.

A limitation of this study is that any investigation based on self-reports (questionnaires) is subject to bias because answers are subjective; however, to the extent possible, the basic validity and reliability requirements were met, which may have helped to assess sleep 
problems in adolescent students.

Also, it was not possible to assess students' ethnic origin and socioeconomic status, although, in general -and in spite of such differencesstudies have demonstrated the presence of sleep disorders in adolescents. ${ }^{30}$

The strengths of this study were that it included a large sample (selected in a probabilistic manner) and also that the instrument development considered five categories to measure sleep disorders comprehensively. Estimations may be done in the following link: http:/ / www.reidebihu.net/, and readers may access three versions of the questionnaire (Spanish, English, and Portuguese).

\section{CONCLUSIONS}

The self-report developed to measure sleep disorders in adolescents is valid and reliable for its use in health, education, and sports science programs. Percentiles should be used to identify normal patterns and / or sleep disorders by sex and age, although, to confirm such outcomes, it is necessary to conduct longitudinal studies and administer the instrument to other ethnic groups from Chile and other countries with similar sociodemographic characteristics.

\section{REFERENCES}

1. Siegel JM. Do all animals sleep? Trends Neurosci. 2008; 31(4):208-13.

2. Chien KL, Chen PC, Hsu HC, Su TC, et al. Habitual sleep duration and insomnia and the risk of cardiovascular events and all-cause death: report from a community-based cohort. Sleep. 2010; 33(2):177-84.

3. Gamble AL, D'Rozario AL, Bartlett DJ, Williams S, et al. Adolescent Sleep Patterns and Night-Time Technology Use: Results of the Australian Broadcasting Corporation's Big Sleep Survey. PLoS One. 2014; 9(11):e111700.

4. Short MA, Gradisar M, Gill J, Camfferman D. Identifying Adolescent Sleep Problems. PLoS One. 2013; 8(9):e75301.

5. Owens J. Epidemiology of sleep disorders during childhood. In Sheldon S, Ferber R, Kryger M, (eds.). Principles and Practices of Pediatric Sleep Medicine. Philadelphia: Elsevier Saunders; 2005.Págs.27-33.

6. Carskadon MA, Vieira C, Acebo C. Association between puberty and delayed phase preference. Sleep. 1993; 16(3):258-62.

7. Gregory AM, Caspi A, Eley TC, Moffitt TE, et al. Prospective longitudinal associations between persistent sleep problems in childhood and anxiety and depression disorders in adulthood. J Abnorm Child Psychol. 2005; 33(2):157-63.

8. Johnson EO, Roth T, Breslau N. The association of insomnia with anxiety disorders and depression: exploration of the direction of risk. J Psychiatr Res. 2006; 40(8):700-8.

9. Bruni O, OttavianoS, Guidetti V, Romoli M, et al. The Sleep Disturbance Scale for Children (SDSC) Construction and validation of an instrument to evaluate sleep disturbances in childhood and adolescence. J Sleep Res. 1996; 5(4):251-61.

10. Meltzer LJ, Avis KT, Biggs S, Reynolds AC, et al. The
Children's Report of Sleep Patterns (CRSP): a self-report measure of sleep for school-aged children. J Clin Sleep Med. 2013; 9(3):235-45.

11. Hysing M, Haugland S, Stormark K, Bøe T, et al. Sleep and school attendance in adolescence: Results from a large population-based study. Scand J Public Health. 2015;43(1):29.

12. Cole TJ, Bellizzi MC, Flegal KM, Dietz WH. Establishing a standard definition for child overweight and obesity worldwide: international survey. BMJ.2000;320(7244):12403.

13. Fernández-Jiménez E, Pérez-San-Gregorio MA, Taylor G, Bagby M, et al. Psychometric properties of a revised Spanish 20-item Toronto Alexithymia Scale adaptation in multiple sclerosis patients. Int J Clin Health Psychol. 2013; 13(3):226-34.

14. Cossio-Bolaños MA, Vasquez P, Luarte-Rocha C, SullaTorres J, et al. Evaluación de la autopercepción de la aptitud física y propuesta de normativas en adolescentes escolares chilenos: estudio EAPAF. Arch Argent Pediatr. 2016; 114(4):319-28.

15. Simões C, Santos S, Biscaia B. Validation of the Portuguese version of the Personal Outcomes Scale. Int J Clin Health Psychol. 2016; 16(2):186-200.

16. Gómez-Campos R, Bersano-Benavides G, Luarte-Rocha C, Tumi Figueroa E, et al. Validación y propuesta normativa para la valoración de la preocupación por la alimentación de adolescentes chilenos: estudio EPACH. Nutr Hosp. 2016; 33(2):337-44.

17. Cortina JM. What is coefficient alpha? An examination of theory and applications. J Appl Psychol. 1993;78(1):98-104.

18. Oviedo HC, Campo-Arias A. Aproximación al uso del coeficiente alfa de Cronbach. Rev Colomb Psiquiatr. 2005; 34(4):572-80.

19. Gómez-Campos R, de Arruda M, Camargo C, Cossio Bolaños M. Confiabilidad de un cuestionario que valora la actividad física en adolescentes normopeso y con exceso de peso. Nutr Hosp. 2015; 31(5):2205-11.

20. Gómez-Campos R, de Arruda M, Sulla J, Alvear F, et al. Construcción de un instrumento para valorar la actitud a la obesidad en adolescentes. Rev Chil Nutr. 2015; 42(3):27783.

21. Gregory RJ. Psychological testing: history, principles and applications. Boston: Allyn and Bacon; 1992.

22. Kułaga Z, Litwin M, Tkaczyk M, Palczewska I, et al. Polish 2010 growth references for school-aged children and adolescents. Eur J Pediatr. 2011; 170(5):599-609.

23. Wing YK, LiSX, Li A.M, ZhangJ, et al. The effect of weekend and holiday sleep compensation on childhood overweight and obesity. Pediatrics. 2009; 124(5):e994-1000.

24. Hart CN, Cairns A, Jelalian E. Sleep and obesity in children and adolescents. Pediatr Clin North Am. 2011; 58(3):715-33.

25. Beebe DW. Cognitive, behavioral, and functional consequences of inadequate sleep in children and adolescents. Pediatr Clin North Am. 2011; 58(3):649-65.

26. Chorney DB, Detweiler MF, Morris TL, Kuhun BR. The interplay of sleep disturbance, anxiety, and depression in children. J Pediatr Psychol. 2008; 33(4):339-48.

27. Gregory AM, Sadeh A. Sleep, emotional and behavioral difficulties in children and adolescents. Sleep Med Rev. 2012; 16(2):129-36.

28. Hysing M, Sivertsen B, Morten-Stormark K, O'Connor R. Sleep problems and self-harm in adolescence. Br J Psychiatry. 2015; 207(4):306-12.

29. Iglowstein I, Jenni OG, Molinari L, Largo R. Sleep duration from infancy to adolescence: reference values and generational trends. Pediatrics. 2003; 111(2):302-7.

30. Vilela TS, Bittencourt LR, Tufik S, Moreira GA. Factors influencing excessive daytime sleepiness in adolescents. J Pediatr (Rio J). 2015; 92(2):149-55. 